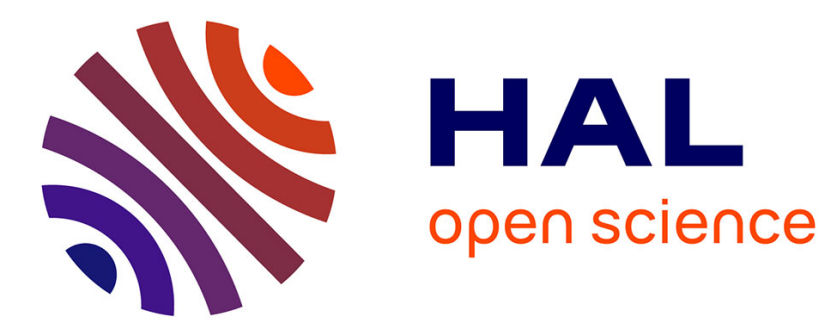

\title{
Collective Oscillating Mode in a One-Dimensional Chain of Convective Rolls
}

M M Dubois, R da Silva, François Daviaud, P Bergé, A Petrov

\section{To cite this version:}

M M Dubois, R da Silva, François Daviaud, P Bergé, A Petrov. Collective Oscillating Mode in a One-Dimensional Chain of Convective Rolls. EPL - Europhysics Letters, 1989, 8 (2), pp.135-139. cea-01374052

\section{HAL Id: cea-01374052 https://hal-cea.archives-ouvertes.fr/cea-01374052}

Submitted on 29 Sep 2016

HAL is a multi-disciplinary open access archive for the deposit and dissemination of scientific research documents, whether they are published or not. The documents may come from teaching and research institutions in France or abroad, or from public or private research centers.
L'archive ouverte pluridisciplinaire HAL, est destinée au dépôt et à la diffusion de documents scientifiques de niveau recherche, publiés ou non, émanant des établissements d'enseignement et de recherche français ou étrangers, des laboratoires publics ou privés. 


\title{
HAL \\ archives-ouvertes. ff
}

\section{Collective Oscillating Mode in a One-Dimensional Chain of Convective Rolls}

\author{
F Daviaud, M Dubois, P Bergé, R Da Silva, A Petrov
}

\section{To cite this version:}

F Daviaud, M Dubois, P Bergé, R Da Silva, A Petrov. Collective Oscillating Mode in a OneDimensional Chain of Convective Rolls. Europhys. Lett., 1989. <cea-01374052>

\section{HAL Id: cea-01374052 \\ https://hal-cea.archives-ouvertes.fr/cea-01374052}

Submitted on 29 Sep 2016

HAL is a multi-disciplinary open access archive for the deposit and dissemination of scientific research documents, whether they are published or not. The documents may come from teaching and research institutions in France or abroad, or from public or private research centers.
L'archive ouverte pluridisciplinaire HAL, est destinée au dépôt et à la diffusion de documents scientifiques de niveau recherche, publiés ou non, émanant des établissements d'enseignement et de recherche français ou étrangers, des laboratoires publics ou privés. 
Europhys. Lett., 8 (2), pp. 135-139 (1989)

\title{
Collective Oscillating Mode in a One-Dimensional Chain of Convective Rolls.
}

\author{
M. Dubois, R. Da Silva, F. Daviaud, P. Berge and A. Petrov \\ Service de Physique du Solide et de Résonance Magnétique de Saclay \\ F-91191 Gif-sur-Yvette Cedex, France
}

(received 22 July 1988; accepted in final form 28 October 1988)

PACS. 47.25Q - Convection and heat transfer.

PACS. 47.20 - Hydrodynamic stability and instability.

PACS. 05.70 - Thermodynamics.

\begin{abstract}
Experiments of Rayleigh-Benard convection in intermediate geometries show that very small wavelengths can be stabilized at very high values of the Rayleigh number when the fluid layer is quasi one-dimensional. A new collective oscillating instability is then observed; this instability may be a first step toward spatio-temporal chaos.
\end{abstract}

Rayleigh-Benard convection has shown itself to be a good system for the study of the transition to turbulence. In small geometries, observations of the dynamical evolution with the Rayleigh number have led to a precise understanding of chaotic behaviours (for example [1-3]). In large geometries, mechanisms leading to turbulence near the onset have been observed, in particular in low Prandtl number fluids; they are related to the spatial properties of the system (for example $[4,5]$ ). The remaining domain, that of intermediate geometries, has been little studied to date; these geometries are nevertheless of interest as they provide systems for the study of the approach to turbulence, starting from the now well-understood concepts of deterministic chaos [6] and adding progressively the notion of space.

Recent theoretical work in this direction is exemplified by numerical studies of coupled map lattices [7] and of partial differential equations derived from the Kuramoto-Sivashinsky model $[8,9]$. The experimental work parallel to the former corresponds to the study of a chain of oscillators, whereas the latter can be applied to observations in a one-dimensional chain of convective rolls; this kind of convection can be achieved experimentally in a convective structure for which one of the horizontal extensions is small and the other great, in comparison with the depth. We report here some striking features, in particular a new collective oscillating state observed in Rayleigh-Benard convection in these intermediate geometries.

The experimental results. - The Rayleigh-Benard convection is achieved in two different geometries: one is rectangular $((180 \times 2 \times 5) \mathrm{mm})$, with aspect ratios $\Gamma_{x}=36$ and $\Gamma_{y}=0.4$ 
and filled with silicon oil of Prandtl number $\simeq 7.5$. The other cell is annular, with internal diameter $120 \mathrm{~mm}$ and external diameter $126 \mathrm{~mm}$ thus having a gap of $3 \mathrm{~mm}$. Its depth is $10 \mathrm{~mm}$, giving an aspect ratio $\Gamma_{\mathrm{R}}=0.3$ along the radius and $\Gamma_{\mathrm{p}}=38.6$ along the circumference. This cell is filled with silicon oil of Prandtl number $\simeq 22$. The walls of both cells are of plexiglass and are between upper and lower copper plates.

The shadowgraphic images of the convective states are observed for both geometries, the beam crossing the cell along the direction parallel to the rolls' axes. The images, observed on a screen (fig. 1), give then a picture of the pattern in a vertical plane. These images are recorded with a CCD camera on a video recorder.

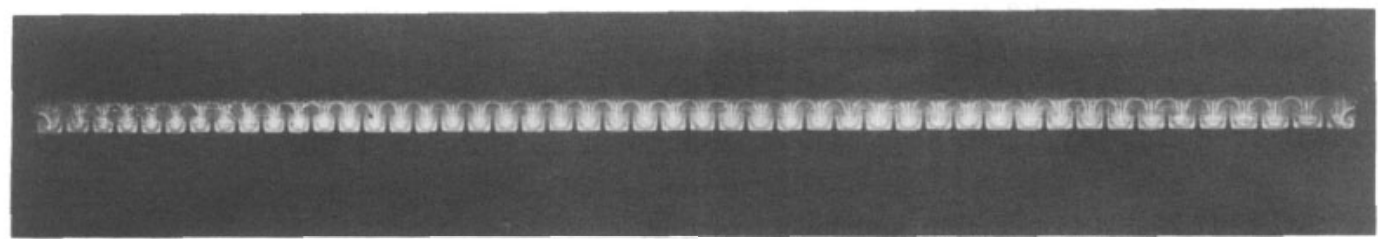

Fig. 1. - Shadowgraphic picture of the rolls in the whole rectangular cell.

In the rectangular cell, a part of the image, along a line parallel to the great extension of the cell, is focused onto a photodiode array of 256 pixels. We may then record the intensity of the pattern at any time by digitizing the photodiodes' signals with an 12-bit ADC controlled by a microcomputer. The resulting time series allow us to follow the spatio-temporal evolutions of the pattern. In the case of the annular geometry, the same kind of information is given by a photodiode which sweeps the circumference at a chosen frequency. In both cases, the array or the mobile photodiode, the intensity is such that a maximum corresponds to cold streams and a minimum to hot streams in the vertical plane.

The convective pattern consists, above the threshold, of a perfect chain of parallel rolls with axes perpendicular to the long side of the cell. At a given Rayleigh number the actual wavelength depends on the previous thermal history; in particular, it is known that when the fluid is subjected to a quick increase of the temperature difference, a stable structure can be obtained with a wavelength lower than $\lambda_{c}[10]$. After such an increase in the temperature difference, we have observed that unusually short wavelengths (as short as $\lambda_{c} / 3$, with $\left.\lambda_{c}=2 d\right)$ can be stabilized in the cells. This situation may be explained by the natural tendency for these geometries to favour wavelengths shorter than $\lambda_{c}$ [11-13]. In addition, it is seen that the smaller the $\Gamma_{y}$ value, the smaller the minimal stabilized wavelength; at least in a certain domain the system appears to exhibit a resonance between the observed short wavelength and the cell width. We may then observe a very nice periodic oscillation of the hot and cold streams as the first time-dependent behaviour above a given value of the Rayleigh number. This kind of oscillating instability corresponds to a fine collective behaviour as can be seen in fig. 2 . If we look at the uprising streams near the hot bottom plate, their individual position oscillates around a mean value. In addition, as cold streams and hot streams oscillate with phase opposition [14], the rolls'size seems to change continuously, from smaller to greater value compared to the mean size. Moreover, there is a phase delay between the streams' motion near the copper plates and their motion at the centre of the fluid layer, so the streams appear to undulate (or to vacillate) in the vertical plane.

The amplitude of the oscillation varies, depending on the roll position in the cell. As seen in fig. 2, some rolls do not oscillate (like nodes of vibrations) defining domains of oscillation inside which there is a smooth spatial modulation of the displacement amplitude. (For the 

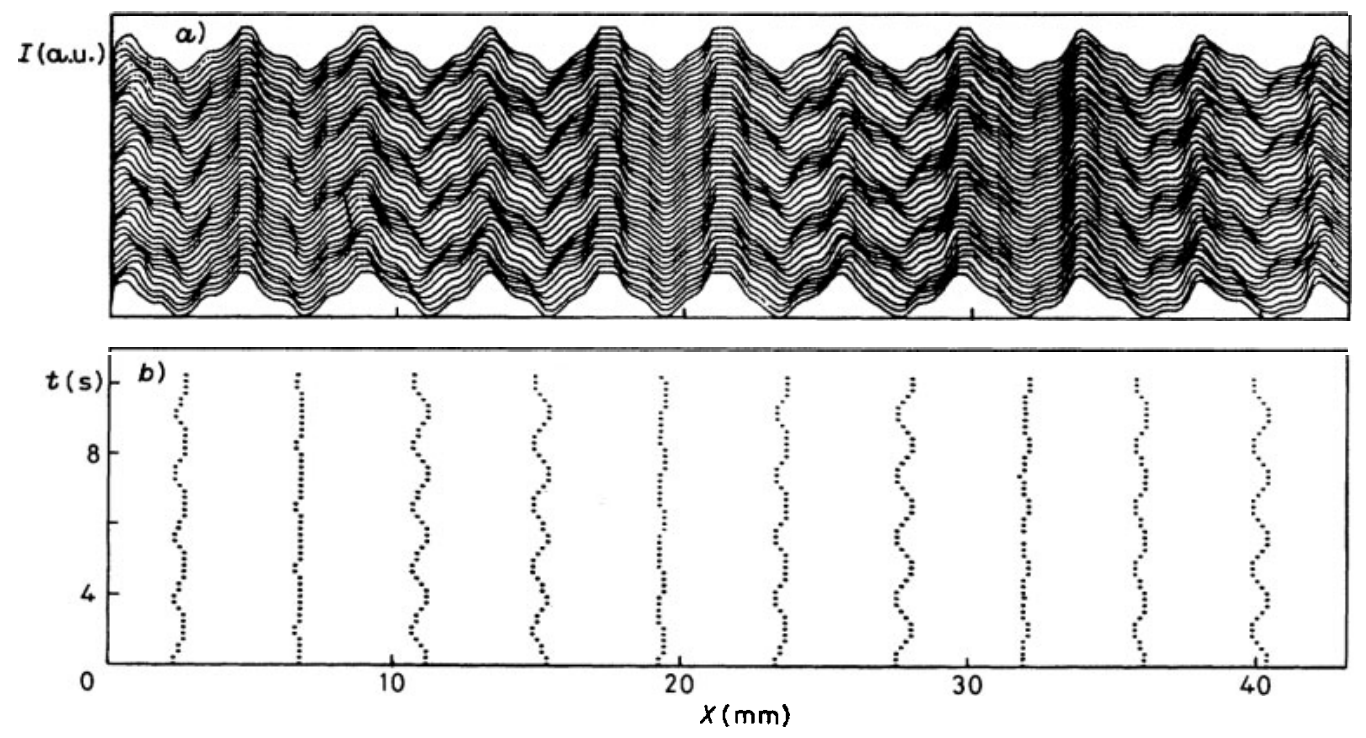

Fig. 2. - a) Space-time evolution of the light intensity measured in the middle of the rectangular cell (21 rolls). Each continuous line is separated by $350 \mathrm{~ms} . R a=1.48 \cdot 10^{6} . b$ ) Space-time evolution of the corresponding minima intensity (hot streams).

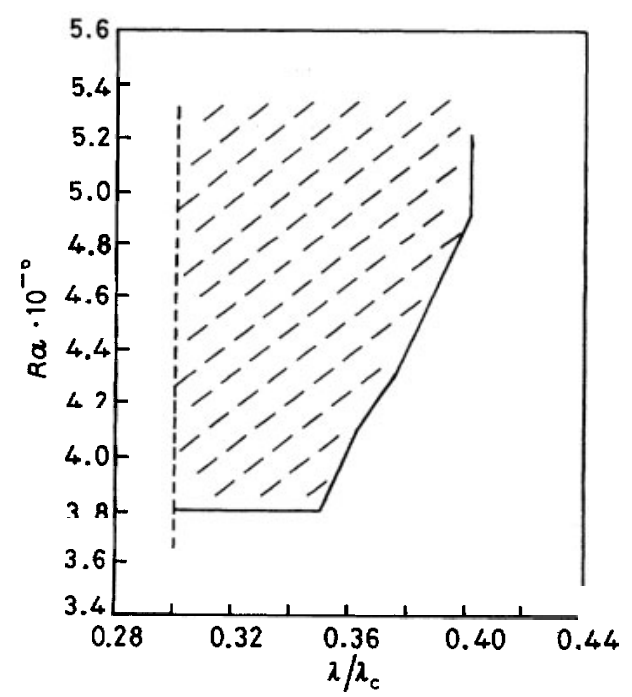

Fig. 3. - Domain of stability of the collective oscillating mode, as observed in the annular geometry. The shaded region corresponds to the domain of oscillation. Wavelengths smaller than $0.3 \lambda_{c}$ have not been stabilized.

example shown in fig. 2 , the maximum displacement is $\delta l \simeq \lambda / 8$.) In the rectangular cell the positions for which the oscillation amplitude is zero are periodic in space and could define a stationary wave with a new characteristic length $\lambda \simeq 6 \lambda_{0}$ if $\lambda_{0}$ is the actual wavelength. The frequency of the oscillations is exactly the same along the entire cell $(\simeq 0.27 \mathrm{~Hz}$ at $R a=1.48 \cdot 10^{6}$ which gives a period of around $1.1 \cdot 10^{-2} d^{2} / D_{\mathrm{T}}$, where $d^{2} / D_{\mathrm{T}}$ is the vertical 
thermal diffusion time) and this perfect coherence can be surprising in a structure numbering 94 rolls. A second very low frequency can also be present (typically $\simeq f_{1} / 50$ with $f_{1}$ the fundamental frequency of the rolls' oscillations). In this case, the second frequency is due to a periodic small displacement of the nodes, i.e. of the position of the nonoscillating streams in the cell.

In the case of the annular geometry $\left(\Gamma_{y}=0.3\right.$ and $\left.\operatorname{Pr}=22\right)$, the same basic phenomenon is observed (with frequency $\simeq 0.13 \mathrm{~Hz}$ at $R a=4.8 \cdot 10^{6}$ which gives a period around 0.58 . $\cdot 10^{-2} d^{2} / D_{\mathrm{T}}$ ). In addition, the relative spacing between periodic nodes is approximately the same for the two geometries. However, for the annular geometry, the wavelength is generally not homogeneous all along the circumference and, in this case, some parts are oscillating and others not. In fact this inhomogeneity reveals in a striking way that the collective oscillation of the streams is very sensitive to the local wavelength. Observations show that the oscillations are present in a very restricted domain of the local wavelength, near the value $\lambda_{c} / 2.5$. The exact domain of stability seems to depend slightly on the Prandtl number and perhaps also on the transverse aspect ratio.

Discussion. - It is important to note that in the studied geometries, which attempt to simulate a one-dimensional chain of rolls, the first time-dependent behaviour which is observed when the Rayleigh number is increased corresponds to a well-ordered motion of the rolls, in particular in the case of the rectangular geometry. As the motion of the hot and cold streams is exactly the same along the entire length of the rolls' axes (observations from above [15]), there appears a tendency for the structure to adapt its local short wavelength to a greater value $\left({ }^{1}\right)$. So we are probably in the presence of an instability in the plane $[R a, a]$, which, to our knowledge, has not yet been revealed by any model. It could be of a nature similar to that of the instabilities studied by Bolton et al. [16], in the case of convection with a moderate Prandtl number fluid. But, in this later case, the horizontal extensions of the fluid layer are considered to be quasi-infinite, i.e. far from our experimental conditions $\left(\Gamma_{y}<1\right)$. Our geometry is closer to Hele-Shaw type, for which an oscillatory instability has been predicted, according to a model of porous medium [17], but for small wave numbers only.

From another point of view, a one-dimensional chain of rolls may be described by equations derived from the Swift-Hohenberg model and for which similar oscillations have been observed numerically [18]. So this collective oscillating instability of the roll pattern, which is also evidenced in experiments using lower Prandtl number fluids [19], seems to be a first step in the destabilization of quasi-one-dimensional chains of rolls, and a prelude to spatio-temporal intermittencies [20-22].

\section{$* * *$}

The authors thank particularly M. A. RUBIo for his active contribution, and P. MANNEVILLE and H. CHATE for constructive discussions. C. Schoukroun and B. OzENDA are also acknowledged for their very efficient assistance.

( ${ }^{1}$ ) The boundary layer appears to have a leading role in initiating the oscillation phenomena discussed. The following observation tests this assumption: if the oil has not been thoroughly degassed, at a high-temperature difference very small bubbles $(\sim 0.1 \mathrm{~mm})$ may appear at the lower plate. For a while they remain trapped within the boundary layer, wherein they describe a striking periodic motion in the horizontal direction. The motion of the bubbles attests for an oscillating motion in the boundary layer. 


\section{REFERENCES}

[1] Gollub J. P. and Benson S. V., J. Fluid Mech., 100 (1980) 449.

[2] Libchaber A., Fauve S. and Laroche C., Physica D, 7 (1983) 73.

[3] Dubois M. and Bergé P., Phys. Scr., 33 (1986) 159; Dubors M., Nucl. Phys. B, 2 (1987) 339.

[4] Pocheau A., Croquette V. and la Gal P., Phys. Rev. Lett., 55 (1985) 1094.

[5] Steinberg V., Ahlers G. and Cannell D., Phys. Scr., 9 (1985) 97.

[6] Bergé P., Pomeau Y. and Vidal C. (Editors), L'ordre dans le chaos (Hermann, Paris) 1984; Order within Chaos (Wiley-Hermann, New York-Paris) 1986.

[7] Chaté H. and Manneville P., Physica D, to appear.

[8] Kuramoto Y. and Tsuzuki T., Prog. Theor. Phys., 55 (1976) 356; Hyman J. M. and Nicolaenko B., Physica $D, 18$ (1986) 113.

[9] Chaté H. and Manneville P., Phys. Rev. Lett., 54 (1987) 112.

[10] Dubois M., Normand C. and Bergé P., Int. J. Heat Mass Transfer, 21 (1978) 999.

[11] Davis S. H., J. Fluid Mech., 30 (1967) 465.

[12] STORK K. and MüLler U., J. Fluid Mech., 71 (1975) 231.

[13] Bensimon D., Phys. Rev. A, 37 (1988) 200.

[14] This kind of behaviour has been found very recently in a theoretical work developed by CoULLET $P$. and Iooss G., private communication.

[15] Petrov A., Dubois M. and Bergé P., to be published.

[16] Bolton C. W., Busse F. H. and Clever R. M., J. Fluid Mech., 164 (1986) 469.

[17] Kvenvold 0., Int. J. Heat Mass Transfer, 22 (1979) 395.

[18] Chaté H. and Manneville P., J. Phys., 47 (1986) 939 (Communication to Journées de Physique Statistique, Janvier 1986).

[19] Daviaud F. and PocheaU A., private communication.

[20] Bergé P., Nucl. Phys. B, 2 (1987) 247.

[21] Ciliberto S. and Bigazzi P., Phys. Rev. Lett., 60 (1988) 286.

[22] Daviaud F., Bergé P. and Dubois M., to be published. 